\title{
STATUS OF SOLUBLE ST2 LEVELS IN SERUM OF HTLV-1 INFECTED INDIVIDUALS
}

\author{
FARnAZ Zahedi AVVAL ${ }^{1}$, Shadi ShOMALI ${ }^{1}$, MOHAMMAD NADRI ${ }^{1}$, \\ REZA BOOSTANI $^{2,3}$, LIDA JARAHI ${ }^{4}$ and MASOUD YOUSSEFI ${ }^{5,6 *}$ \\ ${ }^{1}$ Department of Biochemistry, School of Medicine, \\ Mashhad University of Medical Sciences, Mashhad, Iran \\ ${ }^{2}$ Department of Neurology, Ghaem Hospital, School of Medicine, \\ Mashhad University of Medical Sciences, Mashhad, Iran \\ ${ }^{3}$ HTLV-1 and Associated Diseases Research Center, Ghaem Hospital, \\ Mashhad University of Medical Sciences, Mashhad, Iran \\ ${ }^{4}$ Addiction Research Center, Faculty of Medicine, \\ Mashhad University of Medical Sciences, Mashhad, Iran \\ ${ }^{5}$ Department of Microbiology and Virology, School of Medicine, \\ Mashhad University of Medical Science, Mashhad, Iran \\ ${ }^{6}$ Antimicrobial Resistance Research Center, Bu-Ali Research Institute, \\ Mashhad University of Medical Science, Mashhad, Iran
}

(Received: 29 September 2014; Accepted: 12 February 2015)

ST2 is a member of IL-1 receptor family expressed on Th2 cells and regulates Th2 responces. The gene of ST2 encodes soluble ST2 (sST2) and the transmembrane ST2 (ST2L) isoforms through alternative mRNA splicing. The discovery of IL33/ ST2 signaling pathway, has drawn a great scientific attention to this system. sST2 has been shown to be an indacating factor in various inflammatory conditions. This study aims to evaluate serum sST2 levels in HTLV-1 infected patients. This study included 49 HTLV-1 seropositive cases of which 14 were sympthomatic. Controls consisted of 30 healthy volunteers. SST2 level was measured using a quantitative ELISA assay and the results of the study groups were compared. Corroborating the previous reports, $\mathrm{sST} 2$ was lower in females $(P=0.003)$. The sST2 levels was slightly increased in HTLV-1 patients, though such increase was not statistically significant $(P=0.91)$, in addition sST2 level did not correlate significantly to the disease duration $(P=0.78)$. Despite some other chronic viral infection, HTLV-1 seems not to induce high serum sST2. However owing to relatively high normal variation of sST2 levels and rather small sample size, we stongly recommend further reseach with preferably larger sample size to evalute sST2 in HTLV-1 infected patients.

Keywords: HTLV-1, soluble ST2, interleukin 1

* Corresponding author; E-mail: YoussefiM@mums.ac.ir 


\section{Introduction}

The human T-lymphotropic virus type 1 (HTLV-1), one of the first known human retroviruses affecting 10 to 20 millions people worldwide. HTLV-1 spreads globally and is endemic in Africa, south America, north east of Iran and in some regions of Japan [1]. In about one person out of 20, symptomatic diseases associated with HTLV-1 occurs; among these diseases, adult T-cell leukemia/ lymphoma (ATLL) and HTLV-1 associated myelopathy/tropical spastic paraparesis (HAM/TSP) are clinically more significant $[2,3]$. HAM/TSP a spastic paraplegia has been confirmed to be mainly due to the inflammatory responses in spinal cord [2]. Cytokines are thought to play an important role in neurodegeneration occurring in spinal cord of HAM/TSP patients [4]. High levels of tumor necrosis factor alfa $(\mathrm{TNF} \alpha)$ and a number of cytokines such as interleukine-1 $\beta$ (IL-1 $\beta$ ), IL-1 $\alpha$ and IL-6 have been observed in these patients [5-7].

ST2, also known as IL-1 R4, is a member of the interleukin-1 receptor (IL-1 R) family. ST2 gene encodes two distinict forms of receptors: a long membrane-anchored form (ST2L), which is expressed on mast cells [8], macrophages [9] and T helper type 2 but not Th1 cells [10], and a soluble form (sST2) which is produced through different splicing of the gene [11].

ST2L which is mainly expressed on activated Th2 cells is thought to mediate Th2 effector functions through IL33/ST2 signalling pathway [10]. IL-33 a cytokine belonging to the IL-1 family which plays a critical role in Th2 immune responses, binds to its receptor ST2L and stimulates the target cells $[12,13]$. IL-33 is a multifunctional immunomodulatory cytokine that acts both pro- and anti-inflammatory depending on the disease state or in vitro experimental conditions $[14,15]$. The soluble form of ST2 (sST2) is secreted to the serum and acts as a decoy, negative regulatory receptor, namely binds to the free IL-33 and prevents the IL33/ST2L signaling function. Studies have revealed that stimulation with lipopolysaccharide (LPS), IL-1b, TNF-a and IL-6 induce the production of sST2 $[16,17]$. Also, in murine models induction of sST2 expression has been demonstrated by pro-inflammatory stimuli $[9,18]$.

Elevated serum levels of sST2, have been reported in a wide range of diseases such as autoimmune diseases [19], asthma [20], sepsis and LPS induced inflammations [21], as well as chronic viral infections such as HIV-1 [22]. We hypothesized that due to the Th2 responses during HTLV-1 infection [23], the sST2 might serve as a marker of progression and severity of the disease in particular in HAM/TSP patients, therefore the sST2 levels in HTLV-1 positive individuals including HAM/TSP patients were studied and compared with healthy controls. 


\section{Methods}

\section{Study groups}

A total of 49 HTLV-1 positive cases and 30 healthy individuals participated the study. The mean age $\pm \mathrm{SD}$ and gender distribution of different groups are shown in Table I. All HTLV-1 positive patients were diagnosed by HTLV-1

Table I. The age and sex distribution of three groups

\begin{tabular}{lll}
\hline Group & Sex $(\mathrm{F} / \mathrm{M})$ & Age $($ mean $\pm \mathrm{SD})$ \\
\hline Control $^{1}$ & $10 / 20$ & $38.3 \pm 8.01$ \\
Carrier $^{2}$ & $5 / 30$ & $37.03 \pm 7.96$ \\
Patient $^{3}$ & $9 / 5$ & $45.78 \pm 11.86$ \\
\hline
\end{tabular}

${ }^{1}$ Consists of healthy individual blood donors.

${ }^{2}$ Self-declared healthy volunteer blood donors newly detected as HTLV-1 seropositive.

${ }^{3} \mathrm{HTLV}-1$ positive patients diagnosed and treated as HAM/TSP for several years.

Table II. Characteristics of patients (HTLV-1 ${ }^{+}$with HAM/TSP)

\begin{tabular}{|c|c|c|c|c|}
\hline $\begin{array}{l}\text { Patient } \\
\text { No. }\end{array}$ & $\begin{array}{l}\text { Age } \\
\text { (year) }\end{array}$ & Sex & $\begin{array}{l}\text { Detection time } \\
\quad \text { (year) }\end{array}$ & Medications \\
\hline 1 & 29 & $\mathrm{~F}$ & 3 & $\alpha$-Interferon, Sodium valproate, Corticosteroid \\
\hline 2 & 30 & $\mathrm{~F}$ & 5 & Calcium \\
\hline 3 & 30 & $\mathrm{~F}$ & 15 & ND \\
\hline 4 & 37 & M & ND & ND \\
\hline 5 & 40 & $\mathrm{~F}$ & ND & ND \\
\hline 6 & 42 & $\mathrm{~F}$ & 1 & $\alpha$-Interferon, Sodium valproate, Corticosteroid \\
\hline 7 & 44 & F & 13 & Pregabalin, vitamin $B_{1}$ \\
\hline 8 & 45 & $\mathrm{M}$ & ND & ND \\
\hline 9 & 52 & M & 20 & $\begin{array}{l}\alpha \text {-Interferon, Sodium valproate, Corticosteroid, } \\
\text { Folic acid, Baclofen, Tizanidine }\end{array}$ \\
\hline 10 & 52 & M & ND & $\alpha$-Interferon \\
\hline 11 & 58 & $\mathrm{~F}$ & ND & $\alpha$-Interferon \\
\hline 12 & 58 & M & 2 & $\alpha$-Interferon, Corticosteroid \\
\hline 13 & 65 & $\mathrm{~F}$ & 4 & Calcium \\
\hline 14 & 59 & $\mathrm{~F}$ & 8 & Gabapentin, vitamin E \\
\hline
\end{tabular}

$\mathrm{ND}=$ not defined 
antibody ELISA test and were confirmed with western blot analysis. The general characteristics of the patients are described in Table II.

The control group included 30 healthy blood donors. Controls were confirmed to be seronegative for HTLV-1, HIV and viral Hepatitis. In addition, they filled a questionnaire to reveal any diagnosed inflamatory or other potentially efficacious pathologic condition. Healthy and carrier samples were prepared in Blood Transfusion Organization of Mashhad. Patient samples were obtained from HTLV-1 clinic of neurology department at Ghaem university hospital in Mashhad. Written informed consent from all participants was obtained.

\section{ST2 measurement}

sST2 was measured with Quantikine Human ELISA kit (R\&D Systems) according to manufacturer's instructions. This assay employs the quantitative sandwich enzyme immunoassay technique. Samples were diluted 20-fold for assay and the optical density was measured at $450 \mathrm{~nm}$.

\section{Statistical analysis}

Statistical analysis was performed with SPSS11.5 software. Each result was expressed as mean and standard deviation. Normal distribution of variable was assessed by Kolmogorov-Smirnov test. Independent samples $t$-test and ANOVA were used and a two-tailed $P$ value of $<0.05$ was considered statistically significant in all calculations.

\section{Ethical approval}

All samples were collected in accordance with the Helsinki declaration on human research. The study was reviewed and approved by the ethic committee in vice president of research of Mashhad University of Medical Science (MUMS), Mashhad, Iran.

\section{Results}

The mean age and gender distribution of healthy controls and HTLV-1 seropositive group were matched and no significant difference was observed ( $p=$ 0.84 and 0.06, respectively). Kolmogorov-Smirnov test showed that sST2 distri- 
Table III. Level of sST2 (mean \pm S.D) in HTLV-1 ${ }^{+}$and control groups. Levels are expressed in $\mathrm{ng} / \mathrm{ml}$

\begin{tabular}{lccc}
\hline & $\begin{array}{c}\text { Control } \\
(N=30)\end{array}$ & $\begin{array}{c}\text { HTLV-1 } \\
(N=49)\end{array}$ \\
\cline { 2 - 4 } & & $\begin{array}{c}\text { Asymptomatic } \\
(N=35)\end{array}$ & $\begin{array}{c}\text { Symptomatic } \\
(N=14)\end{array}$ \\
\hline Male & $9.62 \pm 4.69$ & $10.25 \pm 3.62$ & $10.83 \pm 2.72$ \\
Female & $6.6 \pm 2.01$ & $8.04 \pm 0.81$ & $8.70 \pm 3.91$ \\
\hline
\end{tabular}

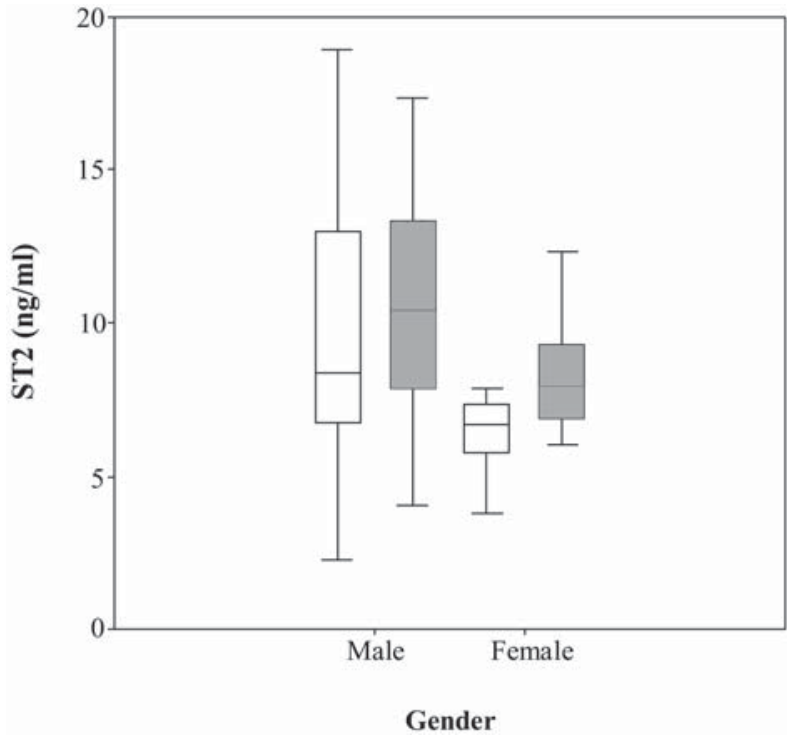

Figure 1. Serum levels of soluble ST2 in HTLV-1 seropositive group (gray box) and healthy controls. Box plots demonstrating gender specific distributions of ST2 plasma consentrations in 24 male and 55 female individuals

bution is normal in control, carrier and symptomatic study groups ( $p=0.289$, $0.872,0.995$, respectively). Table III shows the mean \pm SD of sST2 in different study groups. Statistically no significant diffrence between SST2 levels of controls, carriers and HAM/TSP patients was observed (Anova test, $p=0.384$ ). Moreover, as shown in Figure 1 although an slightly increased sST2 levels in sreopositive groups was observed comparing to healthy controls, such sST2 elevation did not cause significant difference between these groups ( $t$-test, $p=0.91)$.

We also observed lower levels of serum SST2 in healthy females compared to males ( $t$-test, $p=0.02)$ a finding consisting with previous reports $[24,25]$. 
Similarly, a significant difference between the two genders in seropositive carrier group was observed ( $t$-test, $p=0.006$ ). Such difference was also observed when total female measurements were compared to total male values $(t$-test, $p=0.003)$. To exclude the factor of gender, ST2 levels of control and seropositive group were compared in each sex. As shown in Figure 1, increased values were observed in male seropositive cases compared to healthy men, although the difference was not statistically significant ( $t$-test, $p=0.52$ ), a similar finding was observed in females ( $t$-test, $p=0.11)$. The serum sST2 levels in asymptomatic carriers were comparable with those in symptomatic HAM/TSP patients. Likewise, serum level of ST2 in HAM/TSP patients did not show any relation with the duration of symptoms $(p=0.565)$.

\section{Discussion}

In this study we investigated sST2 levels in HTLV-1 infected individuals, the study was performed in north east of Iran where HTLV-1 is endemic [26, 27]. The findings showed an increase trend in chronic HTLV-1 infected individuals compared to healthy controls although the difference was not statistically significant. Still the results should be treated and interperated with caution. Given the high normal variation of sST2 levels in the serum a larger sample size might reveal a significant difference.

The participants of the present study had no history of other known inflamatory conditions or cardiac diseases [28] which might affect their sST2 levels. Previous studies indicate that sST2 level is not significantly influenced by age [24], nevertheless in our study the groups were matched according to their age. On the other hand, gender has a significant effect on serum SST2 levels. Different studies have generally report lower sST2 levels in females [24]. Concerning the effect of gender, various groups were compared on the basis of sex to control this confounding factor, yet, no significant differences were observed.

As mentioned before, high levels of a number of cytokines have been observed in HAM/TSP patients [5-7]. Therefore it seems reasonable to assume that other kinds of cytokines might also contribute in the development of HAM/TSP. In the present study we underscored SST2 production during HTLV-1 infection. However the presented data should be treated as an original idea to propose upcoming studies.

There are several limitations to our study. First, it is limited by a relatively small number of patients. We did not simultaneously measure levels of IL-33 and thus cannot comment on the IL-33/sST2 ratio, which might offer additional 
mechanistic insights. The other important limitation of the study, like many other patient-based studies is lack of information on some potential confounding factors. However, we considered some major confounders and addressed them by a researcher-made questionarie, and it is unlikely that confounding from minor remained underlying factors have greatly affected the results.

To conclude within our study groups, sST2 levels were slightly higher in infected individuals, although such preliminary interpretation merits further confirmatory studies with preferably a higher sample size to assess the pathologic role and clinical relevance of sST2. Such studies should be particularly designed in accordance with disease progression to assess any potential predictive value of sST2 for development of HTLV-1 associated myelopathy.

\section{Acknowledgements}

This study was financially supported by a grant (\#910696) from the research council of Mashhad University of Medical Sciences, Iran. The authors thank to blood transfusion organization of Mashhad, Dr. Reyhaneh Bazargani and Mr. Noori, for their generous assistance in collecting samples.

\section{Conflict of Interest}

The authors have no conflicts of interest.

\section{References}

1. Gessain, A., Cassar, O.: Epidemiological aspects and world distribution of HTLV-1 infection. Front Microbiol 3, 388 (2012).

2. Yamano, Y., Sato, T.: Clinical pathophysiology of human T-lymphotropic virus-type 1-associated myelopathy/tropical spastic paraparesis. Front Microbiol 3, 389 (2012).

3. Yasunaga, J., Matsuoka, M.: Human T-cell leukemia virus type I induces adult T-cell leukemia: from clinical aspects to molecular mechanisms. Cancer Control 14, 133-140 (2007).

4. Allan, S.M., Rothwell, N.J.: Cytokines and acute neurodegeneration. Nature Reviews Neuroscience 2, 734-744 (2001).

5. Kubota, R., Umehara, F., Izumo, S., Ijichi, S., Matsumuro, K., Yashiki, S., Fujiyoshi, T., Sonoda, S., Osame, M.: HTLV-I proviral DNA amount correlates with infiltrating CD4 lymphocytes in the spinal cord from patients with HTLV-I-associated myelopathy. J Neuroimmunol 53, 23-29 (1994). 
6. Nishimoto, N., Yoshizaki, K., Eiraku, N., Machigashira, K., Tagoh, H., Ogata, A., Kuritani, T., Osame, M., Kishimoto, T.: Elevated levels of interleukin-6 in serum and cerebrospinal fluid of HTLV-I-associated myelopathy/tropical spastic paraparesis. J Neurol Sci 97, 183-193 (1990).

7. Tendler, C.L., Greenberg, S.J., Burton, J.D., Danielpour, D., Kim, S.J., Blattner, W.A., Manns, A., Waldmann, T.A.: Cytokine induction in HTLV-I associated myelopathy and adult T-cell leukemia: Alternate molecular mechanisms underlying retroviral pathogenesis. J Cell Biochem 46, 302-311 (1991).

8. Moritz, D.R., Rodewald, H-R., Gheyselinck, J., Klemenz, R.: The IL-1 receptor-related $\mathrm{T} 1$ antigen is expressed on immature and mature mast cells and on fetal blood mast cell progenitors. The J Immunol 161, 4866-4874 (1998).

9. Oshikawa, K., Yanagisawa, K., Tominaga, S-I., Sugiyama, Y.: ST2 protein induced by inflammatory stimuli can modulate acute lung inflammation. Biochem Biophys Res Commun 299, 18-24 (2002).

10. Xu, D., Chan, W.L., Leung, B.P., Huang, F., Wheeler, R., Piedrafita, D., Robinson, J.H., Liew, F.Y.: Selective expression of a stable cell surface molecule on type 2 but not type 1 helper T cells. J Exp Med 187, 787-794 (1998).

11. Iwahana, H., Yanagisawa, K., Ito-Kosaka, A., Kuroiwa, K., Tago, K., Komatsu, N., Katashima, R., Itakura, M., Tominaga, S.: Different promoter usage and multiple transcription initiation sites of the interleukin-1 receptor-related human ST2 gene in UT-7 and TM12 cells. Eur J Biochem 264, 397-406 (1999).

12. Kakkar, R., Lee, R.T.: The IL-33/ST2 pathway: therapeutic target and novel biomarker. Nat Rev Drug Discov 7, 827-840 (2008).

13. Schmitz, J., Owyang, A., Oldham, E., Song, Y., Murphy, E., McClanahan, T.K., Zurawski, G., Moshrefi, M., Qin, J., Li, X., Gorman, D.M., Bazan, J.F., Kastelein, R.A.: IL-33, an interleukin-1-like cytokine that signals via the IL-1 receptor-related protein ST2 and induces T helper type 2-associated cytokines. Immunity 23, 479-490 (2005).

14. Miller, A.M.: Role of IL-33 in inflammation and disease. J Inflamm (Lond) 8, 22 (2011).

15. Miller, A.M., Liew, F.Y.: The IL-33/ST2 pathway - A new therapeutic target in cardiovascular disease. Pharmacol Ther 131, 179-186 (2011).

16. Kumar, S., Tzimas, M.N., Griswold, D.E., Young, P.R.: Expression of ST2, an interleukin-1 receptor homologue, is induced by proinflammatory stimuli. Biochem Biophys Res Commun 235, 474-478 (1997).

17. Tajima, S., Oshikawa, K., Tominaga, S-I., Sugiyama, Y.: The increase in serum soluble ST2 protein upon acute exacerbation of idiopathic pulmonary fibrosis. Chest 124, $1206-$ 1214 (2003).

18. Oshikawa, K., Yanagisawa, K., Tominaga, S., Sugiyama, Y.: Expression and function of the ST2 gene in a murine model of allergic airway inflammation. Clin Exp Allergy 32, $1520-1526$ (2002).

19. Kuroiwa, K., Arai, T., Okazaki, H., Minota, S., Tominaga, S-I.: Identification of human ST2 protein in the sera of patients with autoimmune diseases. Biochem Biophys Res Commun 284, 1104-1108 (2001).

20. Oshikawa, K., Kuroiwa, K., Tago, K., Iwahana, H., Yanagisawa, K., Ohno, S., Tominaga, S.I., Sugiyama, Y.: Elevated soluble ST2 protein levels in sera of patients with asthma with an acute exacerbation. Am J Respir Crit Care Med 164, 277-281 (2001). 
21. Oshikawa, K., Yanagisawa, K., Ohno, S., Tominaga, S-I., Sugiyama, Y.: Expression of ST2 in helper T lymphocytes of malignant pleural effusions. Am J Respir Crit Care Med 165, 1005-1009 (2002).

22. Miyagaki, T., Sugaya, M., Yokobayashi, H., Kato, T., Ohmatsu, H., Fujita, H., Saeki, H., Kikuchi, Y., Tamaki, T., Sato, S.: High levels of soluble ST2 and low levels of IL-33 in sera of patients with HIV infection. J Invest Dermatol 131, 794-796 (2011).

23. Copeland, K.F., Heeney, J.L.: T helper cell activation and human retroviral pathogenesis. Microbiol Rev 60, 722-742 (1996).

24. Lu, J., Snider, J.V., Grenache, D.G.: Establishment of reference intervals for soluble ST2 from a United States population. Clin Chim Acta 411, 1825-1826 (2010).

25. Dieplinger, B., Januzzi, J.L., Steinmair, M., Gabriel, C., Poelz, W., Haltmayer, M., Mueller, T.: Analytical and clinical evaluation of a novel high-sensitivity assay for measurement of soluble ST2 in human plasma - the Presage ST2 assay. Clin Chim Acta 409, 33 40 (2009).

26. Rafatpanah, H., Hedayati-Moghaddam, M.R., Fathimoghadam, F., Bidkhori, H.R., Shamsian, S.K., Ahmadi, S., Sohgandi, L., Azarpazhooh, M.R., Rezaee, S.A., Farid, R., Bazarbachi, A.: High prevalence of HTLV-I infection in Mashhad, Northeast Iran: a populationbased seroepidemiology survey. J Clin Virol 52, 172-176 (2011).

27. Abbaszadegan, M.R., Gholamin, M., Tabatabaee, A., Farid, R., Houshmand, M., Abbaszadegan, M.: Prevalence of human T-lymphotropic virus type 1 among blood donors from Mashhad, Iran. J Clin Microbiol 41, 2593-2595 (2003).

28. Ciccone, M.M., Cortese, F., Gesualdo, M., Riccardi, R., Di Nunzio, D., Moncelli, M., Iacoviello, M., Scicchitano, P.: A novel cardiac bio-marker: ST2: a review. Molecules 18, 15314-15328 (2013). 